DE ECONOMIST 121, NR. 3, 1973

\title{
LABOUR WITH DIFFERENT TYPES OF SKILLS AND JOBS AS PRODUCTION FACTORS
}

B Y

JAN TINBERGEN*

\section{Traditional Treatment of Labour in Macro Production FUNCTIONS}

In macro production functions labour appears as one single factor of production, sometimes accompanied by another factor, education, based either on time series or cross section data. The variable labour is usually introduced as the quantity of labour. This quantity is commonly measured by the number of workers employed, sometimes corrected for changes in the number of hours worked; quality differences between groups of employees are hardly brought into the picture. As a consequence, the light shed on distribution problems with the aid of production functions only concerns income distribution over broad factors such as land, labour and capital. One of the well-known initial findings was that with a Cobb-Douglas production function the share of labour in total income is equal to the exponent given to labour. This exponent has not greatly changed over time, implying that labour income before redistribution constitutes almost a constant portion of national income. The share per income recipient can change, however, if the number of workers does not change proportionally with the total population engaged in production.

* Professor of the Economics of Centrally Planned Systems and Development Programming, Erasmus University, Rotterdam, the Netherlands. - It affords the Board of Editors great pleasure to publish this paper by one of their members. This gives the Board the opportunity, also on behalf of the readers of De Economist. to congratulate Professor Tinbergen most cordially upon his 70th birthday, which he celebrated on 12 th April, 1973. 


\section{New Needs Must Be Met}

Given the increased need for understanding quantitative personal income distributions (as distinct from the distribution over factors), more attention must be given to differences in the quality of labour. Income distribution statistics show that a much larger part of income inequality is due to differences in labour income than to income from capital. Since income can be seen as a price, income distribution will be the outcome of two distributions: one applying to the supply side of the market and one referring to the demand side. In principle the market is the market for all factors of production, but in this essay it will be limited to the labour market and its divisions.

In the last decades a good deal of attention has been given to the supply of labour of different qualities, especially by the 'human capital school' of (mainly American) economists. We owe an admirable survey of the research done until 1970 by this school to one of its leaders, Jacob Mincer [6]. The influence of this school has only slowly penetrated into Europe, however; a fact illustrated by a survey written by the well-known Danish scholar Kjeld Bjerke in the same year [1] in which this group is represented only by one quotation of Mincer from 1958. In the present essay I will follow the human capital school's emphasis on the quantity of schooling received as the most important characteristic of the quality of labour supplied. (This is not to deny that other aspects of quality such as years of experience, has also been considered by them.) I differ from them in my definition of the role of demand. Here the American school tends to use a short term approach, taking employment figures as an index for demand; little attention is given to the feed back of short term employment (or unemployment) to wage or salary levels. A notable exception to this generalization, however, is Freeman's study of the market for college-trained manpower [4]. The aim of my essay is to add a medium-to-long term demand relation to the supply relation. Because of a lack of most other data needed, I shall concentrate on the educational component of the quality of labour. A few remarks about other apects to be given attention in subsequent research will be added in Section 8. 
3. Demand for Types of Skill to Be Incorporated in the Production Function

A demand for labour of varying skill levels is made by the organizers of production. Production should be defined in its widest sense including, for instance, education and the production of public services. Labour demand can be derived from a general production function which expresses national product as a function of the quantities of labour applied in the production process. Even if we stick to the use of only one aspect of the quality of labour, the quantity of schooling, we must differentiate between the schooling normally required for the execution of a given productive task and the actual schooling of the person engaged for that task. In this simple first approach only three levels of eduction will be considered - the first, the second, and the third level - as usually distinguished. The quantities of persons engaged will be expressed by a symbol $\phi_{s v}$ where $\phi$ is the portion of the total active population carrying out tasks for which the level $s(1,2$ or 3$)$ is preferred, but people with level $v$ are being used. Knowing that they will not always succeed in attracting people so that $v=s$, the organizers of production will also try to obtain people when $v \neq s$. They are assumed to know what the contribution of such people to the product will be; this is expressed in the parameters of the production function. In a situation where less people of highest schooling are available than could be used in the production process, a rational behaviour of both the demand and the supply side of the market will imply that $v \leq s$, and the total active population can be represented by the matrix of Table 1 .

\section{TABLE 1}

Matrix of Active Population, assuming (A) Full Employment; (B) [Scarcity of Educated Manpower and (c) Three Levels of EDUCATION

\begin{tabular}{lrcccc}
\hline Actual schooling & $v=$ & 1 & 2 & 3 & Total \\
Schooling & 1 & $\phi_{11}$ & $\cdot$ & $\cdot$ & $\phi_{1 .}$ \\
Required $s=$ & 2 &.$\phi_{21}$ & $\dot{\phi}_{22}$ & $\dot{\phi}_{33}$ & $\phi_{2 .}$ \\
& 3 & $\cdot$ & $\phi_{32}$ & $\phi_{3 .}$ \\
\cline { 2 - 6 } Total & & $\phi_{.1}$ & $\phi_{.2}$ & $\phi_{.3}$ & 1 \\
\hline
\end{tabular}

Although it is conceivable that $\phi_{\mathbf{3 1}} \neq 0$, it is not rational and the actual figure is small enough to be neglected. This means that, 
apart from capital and land, we have five skill levels as inputs in the realm of labour.

\section{Digression on the Possibility of Continuous Distributions OF SKILI.}

A more general approach is conceivable if we assume that both $s$ and $v$ can take any value between a minimum of zero and some maximum $S$ or $V$, meaning that $s$ and $v$ are considered as continuous variables. Instead of the matrix of Table 1 we would then use a twodimensional frequency distribution with densities $\phi(s, v)$, and total manpower could then be written as an integral:

$$
\mathrm{l}=\int_{0}^{s} \mathrm{~d} s \int_{0}^{v} \mathrm{~d} v \phi(s, v)
$$

Such a procedure might be fruitful if $\phi$ can be written as a not too complicated function of $s$ and $v$, for instance, the normal or the lognormal distribution. Moreover, the productive contribution of the element $\phi(s, v) \mathrm{d} s \mathrm{~d} v$ should be known explicitly and be close to a not too complicated function of $s$ and $v$. Exercises with figures for a number of production sectors did not disclose a simple shape for either of these functions and did not encourage B. Herman and myself to follow this procedure. These exercises actually referred to the two production factors of capital (including human capital) and 'pure', (that is, unskilled) labour [5]. In the present essay I therefore stuck to the much simpler discrete-value system expressed in Table 1.

\section{Two Alternative Cobb-Douglas Production Functions in $\phi_{s v}$}

In a first attempt to use a Cobb-Douglas-like production function in $\phi_{s v}$ [7], I introduced (for two values of $s$ and $v$ each) the function:

$$
y=C \phi_{11}^{\rho_{11}} \phi_{12}{ }^{\rho_{12} 2} \phi_{21}{ }^{\rho_{21}} \phi_{22^{\rho_{22}}}
$$

where $y$ represents total national product and $C$ is proportional to the contribution made by the capital stock.

This function has the inconvenience that $y=0$ for $\phi_{12}$ or $\phi_{21}=0$, which is completely unrealistic; hence, the function (5.1) has to be rejected. As factors (in the mathematical meaning of that phrase) we have to introduce sums of $\phi$ 's of either the same $s$ or the same $v$. Accordingly, two alternatives can be formulated in the case de- 
scribed by our Table 1 . If we combine $\phi$ 's with the same $s$, we consider as one production factor the group of people having the same job; if we combine $\phi$ 's with the same $v$, we consider as one production factor the group of people with the same education. In neither case can we simply take the unweighted sums, i.e., $\phi_{21}+$ $+\phi_{22}$ or $\phi_{11}+\phi_{21}$, since the productivity of an individual with an education not intended for the job will differ from the productivity of an individual with the appropriate level of education for the job considered. Of the two alternatives, the former seems best if data on incomes in jobs (or job groups) are available, whereas the latter is to be preferred if data on incomes in relation to education received are available. An additional condition for the application of the former alternative is that jobs must be classified according to the education required. The absence of this sort of data for most countries made me choose in favour of the second alternative, implying that the production function was specified as in Equation (5.2):

$$
y=C\left(\phi_{11}+\pi_{21} \phi_{21}\right)^{\rho_{1}}\left(\phi_{22}+\pi_{32} \phi_{32}\right)^{\rho_{2}} \phi_{33}{ }^{\rho_{3}}
$$

Here $\pi_{21}$ constitutes the productivity ratio between individuals with education 1 on jobs 2 and 1 ; and $\pi_{32}$ that ratio between persons with education 2 on jobs 3 and 2 . Both $\pi$ 's will be $>1$, with an upper limit expressing that the (marginal) productivity on job 2 of an individual with education 1 will be lower than, or at most equal to the (marginal) productivity of an individual with education 2. These assumptions were not made in a previous article on the same subject [9].

In addition, I assume that in a configuration with a very small $\phi_{21}, \pi_{21}$ will be very little above 1 ; similarly for $\phi_{32}$ and $\pi_{32}$. This assumption is based on the underlying assumption that in reality job 1 stands for a group of jobs, of which the most productive one is very close to the least productive job belonging to group 2 . Admittedly, a more precise elaboration of this point of view would be useful.

\section{A Simple Complete Model of Income Distribution}

With the production function introduced in Section 5 we now proceed to the construction of a simple complete model in which both demand for various types of labour and also supply plays a part. Supply behaviour will be based on the utility functions of the 
persons involved. With regard to these functions I shall stick to a treatment introduced and defended at some length elsewhere $[8,9]$. This implies that utility functions contain as variables income after $\operatorname{tax} x_{s v}$ and the indicator of the job chosen $s$, and as a parameter the individual's characteristic $v$; they are of the form:

$$
\omega=\ln \left\{x_{s v}+\frac{1}{2} c_{0}(s-2)^{2}-\frac{1}{2} c_{2}(s-v)^{2}\right\}
$$

where the form as well as the coefficients $c_{0}$ and $c_{2}$ are the same for all individuals. In order that individuals with education 1 are willing to accept either a job 1 or a job 2, the corresponding utilities must be equal for $s=v=1$ and for $s=2, v=1$, implying that:

$$
x_{11}+\frac{1}{2} c_{0}=x_{21}-\frac{1}{2} c_{2}
$$

Similarly, in order that individuals with education 2 are indifferent vis-à-vis jobs 2 and 3 we must have:

$$
x_{22}=x_{32}+\frac{1}{2} c_{0}-\frac{1}{2} c_{2}
$$

Here the $x$ 's are incomes after redistribution; we assume that income after tax is a first approximation of the $x$ 's and replace $x$ by $l-t$, where $l$ is primary income and $t$ is tax paid from $l$. Since the $x$ 's enter into the model only in the shape of $x_{11}-x_{21}$ and $x_{22}-x_{32}$, we only have to use the $t$ 's in the two following equations:

$$
\begin{gathered}
l_{11}-l_{21}=-\frac{1}{2} c_{0}-\frac{1}{2} c_{2}+t_{11}-t_{21} \\
l_{22}-l_{32}=\frac{1}{2} c_{0}-\frac{1}{2} c_{2}+t_{22}-t_{32}
\end{gathered}
$$

In the applications we will add:

$$
\begin{aligned}
& t_{11}-t_{21}=0.15\left(l_{11}-l_{21}\right) \\
& t_{22}-t_{32}=0.25\left(l_{22}-l_{32}\right)
\end{aligned}
$$

where 0.15 and 0.25 stand for the marginal tax rates concerned. Again as a first approximation we shall assume 0.15 and 0.25 to be constant, which is incorrect if large shifts in incomes occur. An important feature of the roles of (6.4) and (6.5) is that they are valid if and only if $\phi_{21} \neq 0$ and $\phi_{32} \neq 0$. In order these $\phi$ to be equal to zero, $x_{21}$ need not be 'as high as required' by (6.2), nor need $x_{32}$ to be 'as high as required' by (6.3); in such cases we may have:

$$
\begin{aligned}
& x_{11}+\frac{1}{2} c_{0}>x_{21}-\frac{1}{2} c_{2} \\
& x_{22}>x_{32}+\frac{1}{2} c_{0}-\frac{1}{2} c_{2}
\end{aligned}
$$

Primary incomes for the five categories of employees will be equal 
to their marginal productivities, where $\pi_{21}$ and $\pi_{32}$ are assumed to be constants for each individual in a given situation:

$$
\begin{aligned}
& l_{11}=\frac{\rho_{1} y}{\phi_{11}+\pi_{21} \phi_{21}} \\
& l_{21}=\frac{\pi_{21} \rho_{1} y}{\phi_{11}+\pi_{21} \phi_{21}} \\
& l_{22}=\frac{\rho_{2} y}{\phi_{22}+\pi_{32} \phi_{32}} \\
& l_{32}=\frac{\pi_{32} \rho_{2} y}{\phi_{22}+\pi_{32} \phi_{32}} \\
& l_{33}=-\frac{\rho_{3} y}{\phi_{33}}
\end{aligned}
$$

Assuming, for the reasons given in Section 5, that as $\phi$ varies, $\pi$ has to approach 1 if the corresponding $\phi$ approaches zero, we put:

$$
\begin{aligned}
& \pi_{21}=1+\alpha_{1} \phi_{21} \\
& \pi_{32}=1+\alpha_{2} \phi_{32}
\end{aligned}
$$

The total number of people with education 1 and with education 2 are given:

$$
\begin{aligned}
& \phi_{11}+\phi_{21}=F_{1} \\
& \phi_{22}+\phi_{32}=F_{2}
\end{aligned}
$$

Finally, we specify that $l_{21} \leq l_{22}$ and $l_{32} \leq l_{33}$, again as discussed in Section 5. Since the $\phi$ 's are the central variables in our model, in view of their role in the production function, we prefer to express the last two conditions in terms of these variables:

$$
\begin{aligned}
1+\alpha_{1} \phi_{21} & \leq \frac{\rho_{2}}{\rho_{1}} \frac{F_{1}+\alpha_{1} \phi^{2}{ }_{21}}{F_{2}+\alpha_{2} \phi^{2} 32} \\
1+\alpha_{2} \phi_{32} & \leq \frac{\rho_{3}}{\rho_{2}} \frac{F_{2}+\alpha_{2} \phi^{2}{ }_{32}}{\phi_{33}}
\end{aligned}
$$

These restrictions constitute constraints on the $\alpha$ 's; whenever they are not fulfilled, we have to drop (6.13) or (6.14) or both and replace them with equations (6.17) or (6.18) or both. 
The model now presented consists of four alternatives, depending on the role of the two restrictions $\left(6.2 / 6.2^{\prime}\right)$ and $\left(6.3 / 6.3^{\prime}\right)$. These alternatives have been tabulated in Table 2 . The problem they all help to solve is to find the unknowns $y, \phi, l, t,{ }^{1}$ and $\pi$, numbering 15 , for which we have equations (5.2), (6.4) through (6.18) and in addition:

$$
\Sigma \phi=1
$$

The number of equations also amounts to 15 .

TABLE 2

Four Alternative Situations of the Solution of the Income Distribution Model

\begin{tabular}{|c|c|c|c|c|c|c|c|c|}
\hline \multirow[b]{2}{*}{ Case } & \multicolumn{2}{|c|}{$\begin{array}{l}\text { Validity of } \\
\text { equations }\end{array}$} & \multirow[b]{2}{*}{$(6.4)$} & \multirow[b]{2}{*}{ (6.5) } & \multirow{2}{*}{$\begin{array}{c}\text { Number } \\
\text { of } \\
\text { equa- } \\
\text { tions }\end{array}$} & \multicolumn{2}{|c|}{ Values of } & \multirow{2}{*}{$\begin{array}{l}\text { Remai- } \\
\text { ning un- } \\
\text { knowns }\end{array}$} \\
\hline & $\begin{array}{l}(6.2) \text { or } \\
\left(6.2^{\prime}\right)\end{array}$ & $\begin{array}{l}\text { (6.3) or } \\
\left(6.3^{\prime}\right)\end{array}$ & & & & $\phi_{21}$ & $\phi_{32}$ & \\
\hline 1 & $(6.2)$ & $(6.3)$ & yes & yes & 15 & $\neq 0$ & $\neq 0$ & 15 \\
\hline 2 & $\left(6.2^{\prime}\right)$ & $\left(6.3^{\prime}\right)$ & no & no & 13 & $=0$ & $=0$ & 13 \\
\hline 3 & $\left(6.2^{\prime}\right)$ & $(6.3)^{\prime}$ & no & yes & 14 & $=0$ & $\neq 0$ & 14 \\
\hline 4 & $(6.2)^{\prime}$ & $\left(6.3^{\prime}\right)$ & yes & no & 14 & $\neq 0$ & $=0$ & 14 \\
\hline
\end{tabular}

\section{The Impact of Education on Income Distribution}

The coefficients and the values of the variables prevailing in the Netherlands around 1960 have been estimated by the author and presented elsewhere [8]. Among the data are the total numbers (expressed as parts of the active population) $F_{1}$ and $F_{2}$ of people with first-level and second-level education, the remainder $1-F_{1}-$ $-F_{2}=\phi_{33}$ representing the portion with third-level education. These three figures amounted to $0.91,0.06$ and 0.03 , respectively. The other data are shown in Table 3 ; in addition we had: $\phi_{21}=0.12$ and $\phi_{32}=0.03$.

TABLE 3

Data of the Income Distribution Model, around 1960

\begin{tabular}{lcccccccc}
\hline Coefficients: & $\rho_{1}$ & $\rho_{2}$ & $\rho_{3}$ & $C$ & $c_{0}$ & $c_{2}$ & $\alpha_{1}$ & $\alpha_{2}$ \\
Values: & 0.648 & 0.088 & 0.064 & 15.0 & 0.63 & 2.84 & 2.3 & 5.0 \\
\cline { 1 - 2 } Source: $[8]$ & & & & & & & & \\
\hline 1 Where $t$ symbolizes $t_{11}-t_{21}$ and $t_{22}-t_{32}$.
\end{tabular}


In the present section I want to illustrate the impact of education on income distribution, assuming the model approximates reality. This will be done by showing some numerical values of the unknowns satisfying the model for higher values of $F_{2}$ and $\phi_{33}$, and consequently lower values for $F_{1}$. This primitive way, having illustrative value only, was chosen because of the complicated nonlinear nature of the equations (5.2), (6.17) and (6.18). In fact some of the unknowns $\phi$ were given prechosen values and the corresponding case position in Table 2 and the values of $F_{1}$ and $F_{2}$, as well as these of the other unknowns, were determined in turn.

The results will be found in Table 4, some comments on which will follow.

\section{TABLE 4}

Values of $F_{1}, F_{2}$ and the Unknowns in the Initial Position A and Three Alternative Positions (B through D)

\begin{tabular}{ccccc}
\hline Case & $\mathrm{A}$ & $\mathrm{B}$ & $\mathrm{C}$ & $\mathrm{D}$ \\
\hline$F_{1}$ & 0.91 & 0.88 & 0.85 & 0.81 \\
$F_{2}$ & 0.06 & 0.08 & 0.09 & 0.11 \\
$\phi_{33}$ & 0.03 & 0.04 & 0.06 & 0.08 \\
\hline$\phi_{21}$ & 0.12 & 0.14 & 0.00 & 0.00 \\
$\phi_{32}$ & 0.03 & 0.032 & 0.00 & 0.00 \\
$l_{11}$ & 5.4 & 6.8 & 6.9 & 7.35 \\
$l_{21}$ & 7.4 & 9.1 &. &. \\
$l_{22}$ & 12.2 & 9.7 & 8.9 & 7.35 \\
$l_{32}$ & 13.7 & 11.2 &. &. \\
$l_{33}$ & 19.0 & 15.0 & 9.7 & 7.35 \\
$y$ & 9.05 & 9.35 & 9.10 & 9.15 \\
\hline
\end{tabular}

Before we draw some conclusions from Table 4, our understanding of the income formation process represented by the model may be facilitated by the following mental experiment. Suppose somebody doubts whether the possibility of substitution between manpower of different education created by the Cobb-Douglas production function makes it at all probable that the mixed groups $\phi_{21}$ and $\phi_{32}$ occur. He might rather think that everybody with education 1 takes a job 1, and similarly for levels 2 and 3. This, however, would lead, in a case of relatively large $F_{1}$ and $F_{2}$, to incomes $l_{11}, l_{22}$ and $l_{33}$ different to the extent that equations (6.2) and (6.3), and hence (6.4) and (6.5), would not be fulfilled in the sense inverse to $\left(6.2^{\prime}\right)$ 
and $\left(6.3^{\prime}\right)$ : their left-hand sides would be smaller than their righthand sides. With such big income differences it would become attractive to a number of people with education 1 to apply for a job 2 and for some people with education 2 to look for a job 3 . Such acts would reduce the income differences until (6.2) and (6.3) are fulfilled; and this is why the mixed groups - or at least one of them - may come into existence. The closer we come to the situation where $F_{1}$, $F_{2}$ and $\phi_{33}=1-F_{1}-F_{2}$ are proportional to $\rho_{1}, \rho_{2}$ and $\rho_{3}$ (Case D), the less will the differences between $l_{11}, l_{22}$ and $l_{33}$ become and then, in fact, there is no need for people to take a job not corresponding to their level of education.

Coming now to a closer look at Table 4 , we must remove at once one possible misunderstanding by establishing that total income includes capital income, which is supposed to be one-fifth of it. This can be seen at once from Case D.

The main conclusion to be drawn from the model - and apart from some of the details discussed in Section 6 - is that if the number of people able to absorb a third-level education amounts to 8 per cent of the active population and those able to absorb a secondary education to 11 per cent, a completely equal income distribution would be possible in so far as education alone determines man's productive capability. ${ }^{1}$

Similarly, if the number of people able to absorb a third-level education is double the number which had such an educational level in 1960 (Case C), an income distribution showing considerably less inequality than the 1960 distribution would be possible: the ratio of $l_{33}$ to $l_{11}$ being about 1.5 as against 3.5 in 1960 . Case B is close to the bounds (6.17) and (6.18), whereas $C$ does not fulfil these bounds, meaning that the mixed $\phi$ 's have to be zero. As a consequence (6.2) and (6.3) (and hence (6.6) and (6.7)) need not be fulfilled either, which results in a considerable fall in $l_{33}$. Case $D$ where $F_{1}: F_{2}: \phi_{33}=\rho_{1}: \rho_{2}: \rho_{3}$ results in complete income equalization.

In view of all this, the question of what portion of the active population is able and willing to absorb a third-level education becomes highly relevant for a judgement of the possibilities of reducing income inequalities. Some contributions to an answer can be found in a study by De Wolff [2] according to which $77 \%$ more than in 1960 would have been able to absorb a secondary education

1 In this case taxes will have to be higher for $s=v=1$ than for $s=v=2$ or 3 . 
and $190 \%$ more than in 1960 to absorb a third-level education. If these figures are correct, the bottle neck would be somewhat greater in secondary than in third-level education, but a situation close to D would be within reach!

\section{Further Research is Needed}

This essay only claims to be a very modest attempt to start research along the lines indicated. Its main restriction lies in its assuming only one feature, the educational one, to be relevant to income. Although there is some evidence, in a study by De Wolff and Van Slijpe [3], that education is the most important among the three factors - education, intelligence and social background - the two latter do also influence income (quite apart from income from capital). Other factors such as used in job evaluation and career planning should have a place in a more realistic theory. It seems of particular importance that the huge material available in scattered sources about the two latter aspects be brought together in statistical form. Income $x$ after redistribution could be estimated more exactly, as has already been done on some occasions. Some well-known possible further refinements are the specification of age, sex, and years of experience. The additional question may be raised how technological development may be introduced into this type of production function. Finally, international comparisons will be useful for various purposes.

\section{REFERENCES}

1. BJERke, $K_{J}$., 'Income and Wage Distributions - Part I, A Survey of the Literature', The Review of Income and Wealth, XVI (1970), p. 235.

2. De Wolff, P., 'Mogelijkheden tot het vaststellen van begaafdheidsreserves', Weekblad van het Genootschap van Levaren aan Nederlandse Gymnasia en Lycea en de RLV, LVII (1963), p. 327 (Dutch: 'Possibilities to Estimate Capability Reserves').

3. De Wolff, P. and VAn SlijPE, A. R. D., The Relation between Income, Intelligence, Education and Social Background, European Meeting of the Econometric Society, September, 1972 (Institute of Actuarial Science and Econometrics, University of Amsterdam), p. 20.

4. Freeman, R. B., The Market for College-Trained Manpower, A Study in the Economics of Career Choice, Harvard University Press, Cambridge, Mass., 1971.

5. Herman, B. and Tinbergen, J., 'Planning of International Development', Proceedings of the International Conference on Industrial Economics, Budapest, 15-17 April, 1970.

6. Mincer, J., 'The Distribution of Labor Incomes: A Survey with Special 
Reference to the Human Capital Approach', The Journal of Economic Literature, VIII (1970), p. 1.

7. Tinbergen, J., 'A Positive and a Normative Theory of Income Distribution', The Review of Income and Wealth, XVI (1970), p. 221.

8. Tinbergen, J., An Interdisciplinary Approach to the Measurement of Utility or Welfare, 5th Geary Lecture, Dublin, 1972.

9. Tinbergen, J., 'Income Distribution over Educational Levels: A Simple Model', to be published in the Philippine Economic Journal.

\section{Summary}

\section{LABOUR WITH DIFFERENT TyPES OF SKILLS AND JOBS AS PRODUCTION FACTORS}

A Cobb-Douglas production function with labour of three different levels of education is proposed. The quantity of labour with primary education is defined as the number of people having jobs requiring primary education plus the number of people with primary education who actually have jobs requiring secondary education, the latter being given a weight above one. An analogous definition applies to the quantity of labour with secondary education, where some people will actually have jobs requiring either second or third-level schooling. A simple model where utility functions developed elsewhere are also involved is used to determine the income distribution over levels of education and jobs for given numbers of labourers with primary and secondary education. Doubling the number of those with second and thirdlevel schooling will reduce income differences to about one half. 